\title{
STATUS OF LMR FUEL DEVELOPMENT' IN THE UNITED STATES OF AMERICA
}

By

R. D. Leggett

Westinghouse Hanford Company
Richland, Washington 99352

L. C. Walters

Argonne National Laboratory

P.O. Box 2528

Idaho Falls, ID 83403-2528

(For presentation at the "International Symposium on

Fuels for Liquid Metal Reactors" to be held in conjunction with the 1992 ANS/ENS Winter Meeting

November 15-20, 1992; Chicago, Illinois USA)

*Work supported by the U. S. Department of Energy, Reactor Systems, Development, and Technology, under contract W-31-109-ENG-38. 
Full Paper

\title{
BTATUS OF LMR FUEL DEVELOPMENT IN THE UNITED STATES OF AMERICA
}

\author{
by \\ R. D. Leggett \\ Westinghouse Hanford Company \\ P. O. Box 1970 \\ Richland, Washington 99352 \\ I. C. Walters \\ Argonne National Laboratory \\ P.O. BoX 2528 \\ Idaho Falls, Idaho 83403-2528
}

(For presentation at the "International symposium on Fuels for Iiquid Metal Reactors" to be held

in conjunction with the

1992 ANS/ENS Winter Meeting

November $15-20,1992$; Chicago, Illinois USA)

\begin{abstract}
Three fuel systems - oxide, metal and carbide - are shown to be reliable to high burnurs and a fourth system, nitride, is shown to have promise for IMR applications. The excellent steady state performance of the oxide and metal driver fuels for FFTF and EBR-II, respectively, as well as that of tens of thousands of test pins is provided. Achieving $300 \mathrm{MWd} / \mathrm{kg}$ in the oxide fuel system throug'n the use of low swelling cladding and duct materials is described and arguments for economic viability are presented. Responses to operational transients and severe overpower events are shown to haje large safety margins and run beyond cladding breach, RBCB, likewise, is shown to be nonthreatening to LMR reactor systems. The Integral Fast Reactor (IFR) concept that utilizes metallic fuel and the commercial viability of this concept are discussed. Results from a joint US-Swiss carbide test that operated successfully at high power and burnup in FFTF are also presented.
\end{abstract}




\section{ABSTRACT.}

Three fuel systems - oxide, metal and carbide - are shown to be reliable to high burnup, and a fourth system, nitride, is shown to have promise for IMR applications. The excellent steady state performance of the oxide and metal driver fuels for FFTF test pins is provided. Achieving $300 \mathrm{MWd} / \mathrm{kg}$ in the oxide fuel system through the use of low swelling cladding and duct materials is described and arguments for economic viability are presented. Responses to operational transients and severe over-power events are shown to have large safety margins, and run beyond cladding breach, RBCB, likewise, is shown to be nonthreatening to LMR reactor systems. The Integral Fast Reactor (IFR) concept that utilizes metallic fuel and the commercial viability of this concept is discussed. Results from a joining US-Swiss carbide test that operated successfully at high power and burnup in FFTF are also presented. 


\section{INTRODUCTION}

This paper discusses the status of the development of US Liquid Metal Reactor (IMR) fuel systems - oxide, metal and carbide/nitride - and provides some insight into fruitful areas for future consideration. There is no doubt that fast breeders can now be built and operated safely and effectively with long life fuel systems ${ }^{1-4}$. There remain, of course, the questions of acceptance of nuclear energy in many countries and of economic competitiveness with other energy sources. Reliably achieving high burnup is one of the more important factors that will make the breeder fuel cycle competitive with that of the LWR. The general cost trends with burnup ${ }^{5}$ are illustrated in Figure 1 for LWRs and LMRs for oxide fuel. It is clear that breeder fuels must achieve core average burnup levels of about $150 \mathrm{MWd} / \mathrm{kg}$ or peak burnups of around $200 \mathrm{MWd} / \mathrm{kg}$.

\section{OXIDE FUEL}

The development of mixed oxide $\left(\mathrm{UO}_{2}-\mathrm{PuO}_{2}\right)$ was the cornerstone of the US program for over 20 years culminating in its performance being fully demonstrated as the driver fuel for the Fast Flux Test Facility (FFTF). Mixed oxide was selected because of the excellent burnup potential of this fuel system; the relative ease of commercial fabrication, since an oxide fuel fabrication industry already existed for light water reactors; and the proven safety response (negative Doppler coefficient) of the oxide system in mitigating overpower transients ${ }^{6}$. Figure 2 surnmarizes the number of oxide pins vs. burnup irradiated in full size assemblies under prototypic conditions in FFTF. The response of pins to off normal events was also examined in the Transient Test Reactor, TREAT, facility and in EBR-II.

\section{Steady state Performance}

Progress in attaining the goal of 150 to $200 \mathrm{MWd} / \mathrm{kg}$ is shown in Figure 3, which summarizes the world's experience for fast reactor mixed-oxide fuel systems. The FFTF which started up in 
1980, was able to capitalize on the highly successful experience of PHEN.LX and PFR, and build on the extensive data base developed from an earlier irradiation test program in EBR-II and GETR ${ }^{1}$. The unique FFTF instrumentation, including coolant temperature and flow measurements for each in-core position, and the capability for in-situ subassembly height measurements and withdrawal loads, provided the support required for rapidly increasing burnup with no risk to the operating efficiency of the plant.

FFTF Reference Fuel: The FFTF reference pin design employs mixed oxide fuel pellets helium bonded to $20 \% \mathrm{CW}$ Type 316 stainless steel,SS, cladding. The smear density is $85 \%$ and the fuel-to-plenum volume ratio is 1.0 . The reference fuel development program was extended through the early stages of FFTF operation to qualify full size components under fully prototypic conditions and to establish a basis for extending allowable lifetime. The commercially fabricated ${ }^{7}$, reference FFTF driver fuel has performed flawlessly $y^{2,3}$ to well beyond the design goal peak burnup of $80 \mathrm{MWd} / \mathrm{kgM}$ since the reactor started routine operation in 1982. The driver fuel experienced no breaches below $100 \mathrm{MWd} / \mathrm{kg}$ and selected assemblies reached $120 \mathrm{MWd} / \mathrm{kg}$ before duct distortion forced their removal. only one breach has occurred in an FFTF fuel pin in a standard FFTF driver fuel assembly and

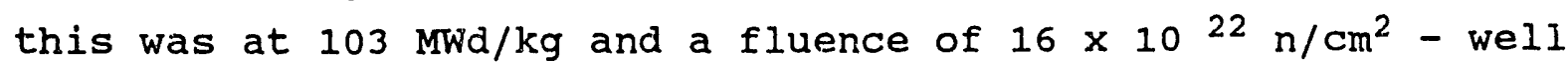
beyond design life.

The testing program showed that ixradiation induced swelling is the life limiting phenomenon in the FFTF driver fuel. For the FFTF fuel system using $20 \% \mathrm{CW}$ Type 316 SS cladding and ducts, a "care-free" residence time to avoid refueling difficulties is a cimulative peak fast fluence (E>0.1 MeV) of about $12 \times 10^{22}$ $\mathrm{n} / \mathrm{cm}^{2}$. Assemblies can be (and are) left in the core beyond this limit, but calculations of withdrawal loads 8,9 are made for sound core management to preclude operating difficulties. Fuel 
management techniques such as rotating and/or shuffling assemblies are used to considerably extend lifetime, as was done with the failed driver fuel assembly described above. Design changes were made to the FFTF driver fuel by using low swelling materials for cladding, ducts and wire wrap to increase lifetime and by going to larger diameter pins in response to design studies for commercial power reactors. The success in extending lifetime for a given duct elongation limit has been spectacular as illustrated in Fig 4. Elongation, of course, reflects only the swelling, as integrated over the length of the duct. Other distortions, such as bow and dilation which have a major influence on withdrawal loads ${ }^{8,9}$, depend not only on swelling but also on irradiation creep and thermal creep. The duct distortions that are routinely calculated for each core load in FFTF are depicted in Fig.5. Each of these distortions has a specific limit 8 associated with it depending on the reactor system of which the assembly is a part.

Extended Lifetime Fuel: Full size assemblies were included in the Cycle 1 core load for FFTF that employed lower swelling, modified austenitic stainless steel alloy D9 for the cladding, wire and duct. All other specifications (dimensions, smeared density, etc.) were identical with the reference FFTF driver

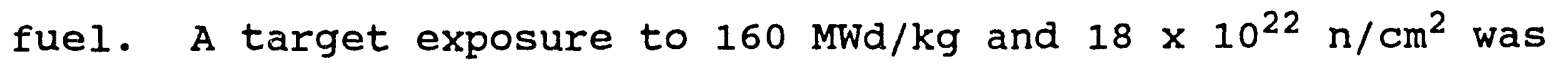
demonstrated and exceeded with the lower swelling D910. Extra lifetime for carefree operation is obtained since the onset of duct distortion is delayed by an increment of about $6 \times 10^{22}$ $\mathrm{n} / \mathrm{cm}^{2}$, thereby allowing higher fluence (and burnup) to be achieved before refueling difficulties are encountered. Actually, mixed-oxide FFTF driver fuel with all D9 components has continued under irradiation in FFTF to a burnup of $188 \mathrm{MWd} / \mathrm{kg}$ and fast fluence of $27 \times 10^{22} \mathrm{n} / \mathrm{cm}^{2}$ showing a large performance margin in this system. For an entire FFTF-like core using D9 components, a very conservative lower exposure limit of $18 \times 10^{22}$ $\mathrm{n} / \mathrm{cm}^{2}$ could be used for routine, "care free" operation. As with 
$20 \% \mathrm{CW}$ type 316 SS components, lifetime can be extended with fuel systems using D9 components by careful core management.

Long Lifetime Fuel: Although D9 offers a large (50-100\%) improvement in fuel assembly lifetime, the material eventually swells, which precludes the achievement of the desired economics of the IMR. Thus, the irradiation of a partial core loading of FFTF known as the Core Demonstration Experiment $(C D E)^{11}$ was begun as an aggressive demonstration of the performance of a fuel system using the zero swelling ferritic alloy HT9 for cladding, wire and duct. The limits of this system have not been established yet, but after a burnup of $238 \mathrm{Mwd} / \mathrm{kg}$ and a fast fluence of $39 \times 10^{22} \mathrm{n} / \mathrm{cm}^{2}$ (this is equivalent to about $200 \mathrm{dpa}$ ) no elongation of the duct occurred (see Figure 4) nor has pin breach been observed 10,12 . There are reasons to believe that burnups of $300 \mathrm{Mwd} / \mathrm{kg}$ will be readily achievable with HT9 components. It may be necessary to slightly increase the pin gas plenum volume in the CDE design but whether or not this will be required won't be known until the lifetime limits of the HT9 system have been reached. It is anticipated that pin breach will be the eventual limiting feature of fuel systems using HT9.

While there is some concern that HT9 has insufficient high temperature strength as fuel pin cladding for all envisioned LMR duty cycles, there is general acceptance 4,9 that HT9 is the choice for a duct (wrapper) material. Furthermore, the lead test for CDE started irradiation at peak cladding temperatures above $600 \mathrm{C}$ (some lead tests were as high as $660 \mathrm{C}$ ) and was progressively moved inward in the FFTF core to maintain a high cladding temperature as burndown progressed. Clearly, HT9 is a leading candidate for both cladding and ducts. Also, ongoing efforts to improve the high temperature strength of HT9 ${ }^{13}$ may provide the designer with the needed assurance to use ferritic components. 


\section{off Normal Performance}

The steady state program has been firmly supported by fuel pin transient testing in TREAT, ${ }^{2,3}$ operational transient tests in EBR-II, 2,14 and run-beyond-cladding-breach (RBCB) studies ${ }^{15}$ in EBR-II. The latter two programs involve collaboration between US-DOE and PNC of Japan.

To define transient performance of mixed oxide fuel, EBR-II pins and full-length FFTF pins were transient tested in the TREAT reactor ${ }^{2,3}$. The exposures included fresh through 118 MWd/kgM, with fluences to $12 \times 10^{22} \mathrm{n} / \mathrm{cm}^{2}$. The overpower transient test ramp rates from $3 \mathrm{C} / \mathrm{s}$ to $3 \$ / \mathrm{s}$ demonstrated excellent failure margin of at least three times steady state power. The tests also provided valuable measurements of fuel melting and pin strain as well as failure, which were used to define performance analysis methods for application to new designs and other transient conditions. When driven to extreme transient conditions necessary to produce pin failure, the fulllength FFTF pins demonstrated desirable failure characteristics. The tests all exhibited upper pin failure locations and axial extrusion of molten fuel above the fuel column; both of which are beneficial safety characteristics that can delay failure and mitigate accident consequences. Fig. 6 summarizes the margins that exist between pin failure and safety shutdown features of the $\mathrm{FFTF}^{3}$. While more than adequate transient margins exists for the fuel system employing austenitic stainless steel components, Figure 6 indicates these margins are increased several additional factors when the ferritic-martensitic, zero swelling hT9 (CDE) is used.

Both the operational transient and $\mathrm{RBCB}$ tests in EBR-II have greatly increased our understanding of the performance of oxide fuel under these respective circumstances, and the fuel response has been very favorable. Several run-beyond-cladding breach programs, the most extensive of which is probably the cooperative 
PNC-DOE program ${ }^{15}$ conducted in EBR-II, have demonstrated conclusively that breaches are benign events and have provided the base data for reactor operators to define their own criteria for shutting down their plant depending on their specific circumstances. This should not be interpreted to mean that the requirements for fuel pin reliability can be relaxed but rather that the operator has some latitude in operating his plant.

The performance of mixed-oxide fuel pins during operational transients has been adequately demonstrated ${ }^{14}$ in the joint DOEPNC program with aggressively designed pins and the response of the fuel is described by computer codes (e.g., LIFE) that were calibrated to actual performance data. The program includes mixed-oxide fuel pins using first-generation cladding $(20 \% \mathrm{CW}$ type 316), second-generation claddings (D9 and PNC-316) and advanced claddings (ferritic-martensitic alloy, $20 \% \mathrm{Ni}$ austenitic stainless steel, and oxide-dispersion ferritic stainless steel). The results demonstrate the capability of second-generation fuel pins to survive a wide range of duty-cycle and extended overpower irradiations. Fuel pins with advanced alloy claddings have been irradiated in EBR-II under steady state conditions and are available for off-normal testing.

\section{METAL FUEL}

During the late 1960's, plutonium bearing metallic fuels were being developed worldwide in an effort to find an acceptable fast breeder fuel.(16) Excellent progress was made toward solution of the problems associated with metallic fuels, e.g.,high swelling and eutectic limitations. Experiments underway would eventually demonstrate that high burnup could be achieved with a reduction in smear density. Further, a U-Pu-Zr alloy possessed not only an adequate solidus temperature with the zirconium additions, but also appeared to exhibit excellent compatibility with stainless steel cladding alloys. (17) At the end of the 1960's, high burnup had not yet been demonstrated for 
metallic fuels and oxide fuel was selected as the fuel system to be used in the next generation of breeder reactors. Available irradiation performance data for $\mathrm{U}-\mathrm{Pu}-\mathrm{Zr}$ pins were promising, however, and a small effort continued at Argonne National Laboratory.

Interest in metallic fuels for liquid metal reactors (LMR) was revitalized when the Integral Fast Reactor concept (IFR) was introduced in 1984. For a number of reasons, metaliic fuel as opposed to ceramic fuels was an essential feature of the IFR concept. Since metallic fuels have high thermal conductivity, fuel pin temperatures are low. Thus, during a loss-of-flow event, the doppler reactivity feedback is small causing but a small temperature rise of the core. This inherent safety feature of metallic fueled cores was demonstrated in 1983 in EBR-II. (18)

Further, metallic fuels lead to an economical, and proliferation resistant fuel reprocessing scheme. Metallic fuels are readily dissolved and electrorefined in a molten salt electrolyte. The removal of fission products during electrorefining is sufficiently complete, with a decontamination factor of about eight, for reintroduction of the refined uranium and plutonium into the reactor, but yet the refined product remains highly radioactive. (19) The process is thus accomplished remotely in a hot cell, whereby diversion of the product is impossible. In addition, unless further expensive refining is carried out, the product is useless for weapons.

Finally, the LMR as originally conceived, can be a breeder for utilization of the vast ${ }^{238} \mathrm{U}$ resources. Metallic fuels are by far the best choice for a high breeding efficiency because of the high energy neutron spectrum.

The IFR concept is dependent upon a plutonium bearing metallic fuel alloy because of plutonium breeding. Wher the IFR 
concept was introduced in 1984 a great deal was known about the U-5Fs* metallic fuel that had been the standard fuel for EBR-II since it went critical in 1964. The performance of U-5Fs fuel has recently been extensively reviewed.(20) During the course of utilizing the U-5Fs fuel in EBR-II, significant but simple design changes were made that allowed a ten-fold increase in burnup and robust performance during off-normal events. The smear density was decreased from $85 \%$ to $75 \%$ to allow interconnection of fission-gas bubbles and subsequent gas release to a much enlarged gas plenum. High burnup and excellent off-normal performance, including benign run-beyond-cladding-breach ( $R B C B$ ) performance were thus assured with the large data base as a result of the irradiation of many EBR-II cores between 1964 and 1984. It was then necessary to demonstrate that U-Pu-Zr fuel possessed similar performance characteristics.

\section{Restoration of Fuel Fabrication Capabilities}

Before any of the performance issues could be addressed, a facility was required to fabricate $\mathrm{U}-\mathrm{Pu}-\mathrm{Zr}$ fuel. The facilities used for this purpose in the 1960's had long since been dismantled. Fuel was needed for irradiations, for basic property studies and, further, the facility was required to gain fuel casting experience.

A glovebox facility was constructed at the Argonne National Laboratory in Idaho. The large, three compartment glovebox, contained a small injection casting furnace, a cladding closure-weld apparatus, and fuel pin characterization equipment. The injection casting furnace could contain a one kilogram charge and cast as many as six fuel slugs up to $50 \mathrm{~cm}$ in length. The construction of the facility, called the Experimental Fuels

*Fissium (Fs) is an equilibrium concentration of fission product elements left by the pyrometallurgical reprocessing cycle designed for EBR-II and consists of $2.4 \mathrm{~W} . \%$ molybdenum, 1.9 wt. $\frac{\%}{6}$ ruthenium, 0.3 wt. $\%$ rhodium, 0.2 wt. $\%$ palladium, 0.1 wt. $\%$ zirconium, and 0.01 wt. $\%$ niobium of the total mass. 
Laboratory (EFL) was completed in the fall of 1984 and the first fuel elements placed under irradiation in the early spring of 1985 in EBR-II. Since that time, valuable fabrication information on casting parameters and closure-welds on the cladding have been accumulated.

\section{Irradiation Experiments}

The first three subassemblies of IFR fuel irradiated in EBR-II all contained the same complement of fuel elements using advanced cladding alloy D9. The only variable in the experiments was the plutonium ancentration in the fuel, where two plutonium concentrations were chusen, 8 and 19 at. $\%$ along with a U-Zr alloy with no plutonium. The zirconium concentration was the same for all the fuel at 10 wto with the balance being uranium. These three subassembiies were used to gain a wealth of performance information with the first breach occurring at 18.4 at.\% burnup. (21)

Soon after, these three subassemblies were put into EBR-II an assembly was fabricated for irradiation in FFTF. A series of issues were raised that could best be addressed by irradiating IFR fuel in FFTF. The primary issue involved the question of extrapolating fuel performance results from EBR-II with a fuel length of $34 \mathrm{~cm}$, to the longer cores of proposed commercial reactors of $90 \mathrm{~cm}$ or more. Extent of axial fuel growth, fraction of fission gas release to the plenum, migration of fuel components, and the stress from fuel-cladding mechanical interaction are all aspects of fuel performance that could be fuel length dependent. Since it is necessary to enrich with ${ }^{235} \mathrm{U}$ for EBR-II irradiations, a secondary issue involved the potential for variation in fission product effects depending on $U$ or $P u$ fission. Accordingly, an assembly for FFTF was fabricated that duplicated the first three subassemblies irradiated in EBR-II. The cladding was D9 and several ternary fuel compositions of 8 and 19 wto plutonium vere included with the binary U-10zr alloys. 
The operating conditions (power and temperature) also approximated those in the first three subassemblies in EBR-II. The assembly was irradiated to 10.2 at. $\%$ burnup in FFTF without failure. Post irradiation examination is currently in progress. Thus far, observed fuel performance results have been consistent with thu EBR-II information. (22)

A number of subassemblies have subsequently been irradiated in EBR-II to meet various objectives, including tests to examine design options, experiments on prototype designs, and tests to validate the fuel specification.(21) In addition, a series of tests were initiated to study the run-beyond-cladding-breach (RBCB) performance of metallic fuel. (23) The highest burnup achieved to date is 19.3 at. $\%$ burnup on fuel elements still under irradiation. Table I shows the number of IFR fuel elements that have been irradiated to date.

Transient overpower tests on metal fuel pins also have been performed in the TREAT facility. (24) Results showed robust overpower capabilities with cladding failure threshold about 4 times nominal power.

Additional testing of long metal-fueled pins has been conducted in the FFTF, as discussea in a companion paper. 25 Seven full size fuel assemblies containing $U-Z r$ fuel slugs loaded in non-swelling ferritic/martensitic HT9 cladding have been irradiated under aggressive conditions [high power $(548 \mathrm{w} / \mathrm{cm}$ ) and temperature $(640 \mathrm{C})$ ] without failure to burnup levels ranging from 38 to $143 \mathrm{MWd} / \mathrm{kg}$ (fast fluence to $20 \times 10^{22} \mathrm{n} / \mathrm{cm}^{2}$ ). The duct and wire-wrap material in these test assemblies is also HT9. These assemblies originally supported the use of U-10Zr as a potential driver fuel for FFTF but the results will also support the design of the U.S./DOE Advanced Liquid Metal Reactor (ALMR), which utilizes long fuel pins containing ternary (U-Pu-Zr) metal fuel in HT9 cladding and ducts. Postirradiation examination of these 
tests will provide data in fuel column growth, fuel and sodium bond performance, cladding strain behavior, fuel-cladding mechanical interaction, and other performance attributes. With continued FFTF operation, ultimate burnup capabilitie and breach mode in long metal fuel pins will be determined.

\section{Property studies and Performance Analysis}

A complete understanding of the $\mathrm{U}-\mathrm{Pu}-\mathrm{Zr}$ fuel system was not achieved when the program was terminated in the 1.00 's. Also, the interaction between fuel and candidate cladding materials required further evaluation. It was essential to understand phase r:lationships in the U-Pu-Zr system in order to know the fuel solidus temperature for reactor design purposes, and to know the liquidus temperatures for fuel casting needs. Good progress has been made in both experiment and thermodynamic analyses of the fuel system. $(26,27)$ A complementary series of tests and analyses to understand the radial migration of fuel components is also well underway.(28) Therefore, the performance of $\mathrm{U}-\mathrm{Pu}-\mathrm{Zr}$ fuel is reaching an advanced state of understanding.

Fuel-cladding compatibility is being studied by use or the fuel-performance-test apparatus (FPTA). Sections of irradiated fuel and cladding are heated along prescribed temperature ramps and held wt peak temperatures for various times. The information gained from these tests includes the temperature where a liquid phase first forms between fuel and cladding, and the rate of penetration of the cladding once a liquid phase forms. These tests are complemented with experiments where entire irradiated fuel elements are subjected to temperature ramps and hold times representative of possible off-normal events. These tests are called whole pin tests (WPT). The combined testing program and subsequent analyses provide a strong base to understand and predict fuel performance during off-normal situations. $(29,30)$ 
The focal point for much of the ex-core analyses is the development of the LIFE-METAL steady-state performance code and the F-PIN transient code for metallic fuel. $(29,30)$ These codes have been under development for a number of years and have now reached a point where reliable predictions can be made. For example, both codes are used for predictions of the WPT tests with remarkably c,ood results.

\section{Future Direction}

Since the restart of metallic fuel development in 1984, most of the performance questions that remained from the 1960's have been answered. It is now apparent that metallic fuel is a viable commercial option, and furthermore, the use of motallic fuel is central to the IFR reprocessing technology. Two main tasks remain to be completed. The first is to demonstrate the same performance characteristics on metallic fuel that has been remotely reprocessed. This demonstration will begin in about a year when the Fuel cycle Facility begins operation at Argonne National Laboratory in Idaho Falls, Idaho. At that time, the entire core of EBR-II will be converted to U-Pu-Zr fuel, which will be irradiated, reprocessed, and reirradiated.

The second main task is the completion of the compilation of all the fuel performance information in a form suitable for the defense of licensing questions and in a form adequate for the design of new LMR's. Several efforts are progress to accomplish this task. A Metallic Fuels Handbook is in its third revision where it will not only include fuel and cladding property data, but also irradiation performance information. A computer base is nearing completion where all the information generated is stored for ready recall for an anticipated wide variety of analyses. Finally a fuel specification has been developed that will be revised and refined as experience is gained on the performance of reprocessed metallic fuel. 


\section{CARBIDE/NITRIDE FUEL}

The physical and irradiation performance characteristics of carbide and nitride fuel have much in common and the information from one fuel system frequently (in a general sense) applies to the other.

Carbide fuel was selected as the driver fuel for the Indian Fast Reactor and has performed well $1^{31}$ but the only work on carbide fuel in the US since that reported on in Tucson in $1986^{2}$ has involved a joint US-Swiss irradiation test in FFTF ${ }^{32,33}$ that irradiated (UPu)C pellets and microspheres in D9 cladding. The 91 pin assembly operated successfully at an initial $83 \mathrm{~kW} / \mathrm{m}$ peak linear power to a burnup of $85 \mathrm{MWd} / \mathrm{kgM}$. Postirradiation examinations ${ }^{34}$ show excellent performance of both types of fuel. These examinations included measurements of pin length, fuel column length, pin diameter profiles, gamma radiation profiles, and fission gas release, and detailed metallography. All observations were within the established data base for mixecicarbide fuel and demonstrate the capability of carbide fuels for providing reliable operation with high power densities for fast reactor application.

The adaption by the space Power Program of UN fuel 35,36 and the recent world-wide interest in $(\mathrm{U}, \mathrm{Pu}) \mathrm{N}$ has sparked some limited evaluations(37) in the US of the potential for application of this fuel system to LMR's. The earlier EBR-II program with mixed nitride fuel ${ }^{38}$ suggested a burnup potential of 20 at. $\%$ at very high $(100 \mathrm{~kW} / \mathrm{m})$ linear heat ratings. Interestingly, nitride fuel exhibits many of the same desirable characteristics of metal fuel, i.e. high heavy metal atom density, good thermal conductivity and excellent compatibility with sodium. It has the added advantage of being compatible with existing fabrication and reprocessing methods established for oxide fuels. The excellent performance of nitride fuel in the Space Power program, the expected similarity in behavior to carbide fuel and foreign irradiation programs will continue to be 
monitored closely for potential consideration in the future US LMR program.

\section{CONCLUSIONS}

The US program has determined:

1) bundle and duct distortion due to neutron induced swelling limits the lifetime of fuels systems using austenitic type 316 ss and the advanced austenitic D9 alloy to about $12 \times 10^{22} \mathrm{n} / \mathrm{cm}^{2}$ and $18 \times 10^{22}$, respectively or about 100 to $150 \mathrm{MWd} / \mathrm{kg}$.

2 ) the oxide fuel system is capable of burnups in excess of $200 \mathrm{MWd} / \mathrm{kg}$ using very low swelling HT9 as the cladding, duct and wire wrap as was demonstrated with the Core Demonstration Experiment (CDE) in FFTF which consisted of ten fuel and six blanket assemblies plus four other fuel assemblies of the same design.

3) the Integral Fast Reactor (IFR) concept employing the ternary U-Pu-Zr metal fuel alloy is the mainline US program for LMR's and has been shown to be commercially viable.

3) mixed-carbide fuel has the capability to provide reliable operation to high burnup at extremely high Iinear powers.

4) mixed-nitride fuel shows promise for future $L M R$ application. 


\section{REF ERENCES}

1. American Nuclear Society, International Conference on Fast Breeder Reactor Fuel Performance, Monterey, California, 1979 .

2. American Nuclear Society, International Conference on Reliable Fuels for Liquid Metal Reactors, Tucson, Arizona, 1986 .

3. American Nuclear Society, Proceedings of IMR: A Decade of Progress and Promise, held during the ANS winter Meeting, November 11-15, 1990, Washington, D.C.

4. BNES, Fast Reactor Core and Fuel Structural Behavior, Inverness, Scotland, 1990 .

5. Leggett, R. D. and R. P. Omberg, Mixed-oxide Fuel Development, ANS, 1987, Experience Gained and Path to Economical Power Generation, Richland, Washington.

6. Arterburn, J. O., et al, SEFOR operating Experience, ASME Nuclear Engineering Conference, Palo Alto, CA, March 1971.

7. Williams, J.F. and I.H. Rice "Fuel Pin Fabrication for the FFTF", Trans. ANS Vol. 34 pp. 221-223, June 1980 (Las Vegas, Nevada)

8. Sutherland, H., "Calculation Methods For Core Distortions And Mechanical Behavior", IAEA IWGFR Specialists Meeting, Mottram Hall, South Manchester, England, October, 1984 .

9. Hecht, S.L., and R.G. Trenchard, "Fast Flux Test Facility Core Restraint System Performance", BNES, Fast Reactor Core and Fuel structural Behavior, Inverness, Scotland, 1990 .

10. Baker, R.B., F.E. Bard, R.D. Leggett, and A.I. Pitner, "Status of Fuel, Blanket, and Absorber Testing in the Fast Flux Test Faci'ity", Proceedings of the "International Syanosium" on Fuels for Liquid Metal Reactors", held during the November 1992 ANS/ENS meeting in Chicago, Illinois, to be published in a special issue of $\mathrm{J}$. Nuc. Mat.

11. Laidler, J.J. and R. J. Jackson, "Long-Lifetime Liquid Metal Reactor Mixed oxide Fuel Demonstration", Trans. ANS, Vol. 47, p. 190, November 1984, Washington, DC. CDE ANS 184 
12. Bridges, A.E., R.D.Leggett, R.B.Baker, A.E.Waltar, and B.C.Gneiting, "Advanced Liquid Metal Reactor Fuel and Blanket Designs Using HTg", Proceedings of the International Conference on Fast Reactors and Related Fuel Cycles, Kyoto, Japan, october 28 - November 1, 1991.

13. Nomura, S., S. Shikakura, S. Ukai, I. Seshimo, M. Harada, I. Shibahara, and M. Katsuragawa, "Development of Long Life FBR Core Materials", Ibid.

14. Boltax, A., L.A. Neimark, H. Tsai, M. Katsuragawa and S. Shikakura, "Reliability of Fast Reactor Mixed-oxide Fuel During operational Transients", Ibid.

15. Strain, R.V., J.H. Bottcher, K.C. Gross, J.D.B. Lambert, S. Ukai, S. Nomura, S. Shikakura, and M. Katsuragawa, "Status of RBCB Testing of LMR oxide Fuel in EBR-II", Ibid.

16. Kittel, J. H., et.al., "Plutonium and Plutonium Alloys as Nuclear Fuel Materials," Nuc. Eng. Des., 15, 373 (1971)

17 Walter, C. M., Golden, G. H., olson, N. J., "U-Pu-Zr Metal All: A Potential Fuel for IMFBR's," ANL-76-28, Argonne Nat: unal Laboratory

18. Mohr, D., Chang, L. K., Feldman, E. E., Betten, P. R., Planchon, H. P., The Experimenta? Breeder Reactor II Inherent Safety Demonstration," Nuc. Eng. Des., 101, $11(1987)$

19. Burris, L., Steunonberg, R. K., and Miller, W. E., "The Application of Electrorefining for Recovery and purification of Fuel Discharged from the Integral Fast Reactor." AICHE Symposium Services, 83135 (1987)

20. Walters, L. C., Seidel, B. R., Kittel, J. H., "Performance of Metallic Fuels and Blankets in Liquid-Metal Fast Breeder Reactors," Nuc. Tech., 65, 179 (1989)

21. Pahl, R. G., Porter, D. L., Crawford, D. C., Walters, I. C., "Irradiation Behavior of Metallic Fast Reactor Fuels," J. Nuc. Mat., 188, 3 (1992)

22. Tsai, H., Neimark, L. A., "Irradiation Performance of FullLength Metallic IFR Fuels," Proceedings Intl. Conf. on Design and Safety of Advanced Nuclear Power Plants, Oct. 2529, 1992, Tokyo, Japan 
23. Batte', G. L., Hofman, G. I., Run-Beyond-Cladding Breach (RBCB) Test Results for the Integral Fast Reactor (IFR) Metallic Fuel Program," Proceedings of 1990 International Fast Reactor Safety Meeting, Snowbird, Utah, Aug. 12-16, 1990

24. Bauer, T.H., et al, Behavior of Modern Metallic Fuel in TREAT Transient Overpower Tests, Nuc. Tech., vol. 92, p. 325, December 1990 .

25. Pitner, A.I. and R.B. Baker, Metal Fuel Test Program in the FFTF, "Proceedings of the International Symposium on Fuels for Liquid Metal Reactors", held during the November 1992 ANS/ENS meeting in Chicago, Illinois, to be published in a special issue of $\mathrm{J}$. Nuc. Mat.

26. Leibowitz, L., and Blomquist, R. A., "Thermodynamic Modeling of the Phase Equilibrium of the Plutonium-Uranium System," J. Nuc. Mat., 184, 59 (1991)

27. Leibowitz, L., Blomquist, R. A., and Pelton, A. D., "Thermodynamics of the Uranium-Zirconium System," J. Nuc. Mat., 167, 76 (1989)

28. Perri, M. C., Hins, A. G., Sanecki, J. E., and Dayananda, M. C. "Uranium-Plutonium Interdiffusion at $7500 \mathrm{C}$ " Submitted for publication in J. Nuc. Mat.

29. Kramer, J. M., Liu, Y. Y., Billone, M. C., and Tasi, H. C., "Behavior of Metallic Fast-Reactor Fuels During Extended Transients," this issue of J. Nuc. Mat.

30. Liu, Y. Y., Tsai, H. C., Billone, M. C., and Kramer, J. M., "Behavior of EBR-II Mk-V-Type Fuel Elements in simulated Loss-of-Flow Tests," this issue of J. Nuc. Mat. -

31. Bhoje, S. B., et al. "Commissioning of Fast Breeder Test Reactor". International Conference on Fast Reactors and Related Fuel Cycles, Kyoto, Japan, October 28 - November 1, 1991.

32. Alder, H. P., et al., "Status of Advanced Fuel Development in Switzerland", ANS Winter Meeting, San Francisco, California, November 28 - 30, 1989.

33. Latimer, T.W., K.M. Chidester, G. Ledergerber, and F. Ingold, "AC-3 Test Design and Fuel Fabrication", Proceedings of the "International Symposium on Fuels for Liquid Metal Reactors", held during the November 1992 ANS/ENS meeting in Chicago, Illinois, to be published in a special issue of $\mathrm{J}$. Nuc. Mat. 
34. Hoth, C.W., R.E. Mason, B.J. Makenas, R. Wisner, and F. Bota, "AC-3 Irradiation Conditions and Non-destructive Examinations", Ibid.

35. Cox, C. M., D. S., Dutt, and R. A. Karnesky, "Fuel systems for compact Fast space Reactors," Space Nuclear Power systems 1984, Proceedings of the First symposium on Space Nuclear Power Systems, January 11-13, 1984, Vol. 2, p. 301, Albuquerque, New Mexico.

36. Matthews, R. B., "Overview of SP-100 Fuel Development Activities," Trans. of the Seventh Symposium on space Nuclear Power systems, CONF-900109, held in Albuquerque, New Mexico, 1990.

37. Lyon, W.F., R.B.Baker, R.D.Leggett, and R.B.Matthews, "Advancing' Liquid Metal Reactor Technology With Nitride Fuels", Proceedings of the International conference on Fast Reactors and Related Fuel Cycles, Kyoto, Japan, october 28 - November 1, 1991.

38. Bauer, A. A., Cybulskis, P., Petty, R. L., Demuth, N. S., "Helium-and-Sodium-Bonded Mixed-Nitride Fuel Performance," Proceedings of the International Conference on Fast Breeder Reactor Fuel Performance, Monterey, California, 1979 


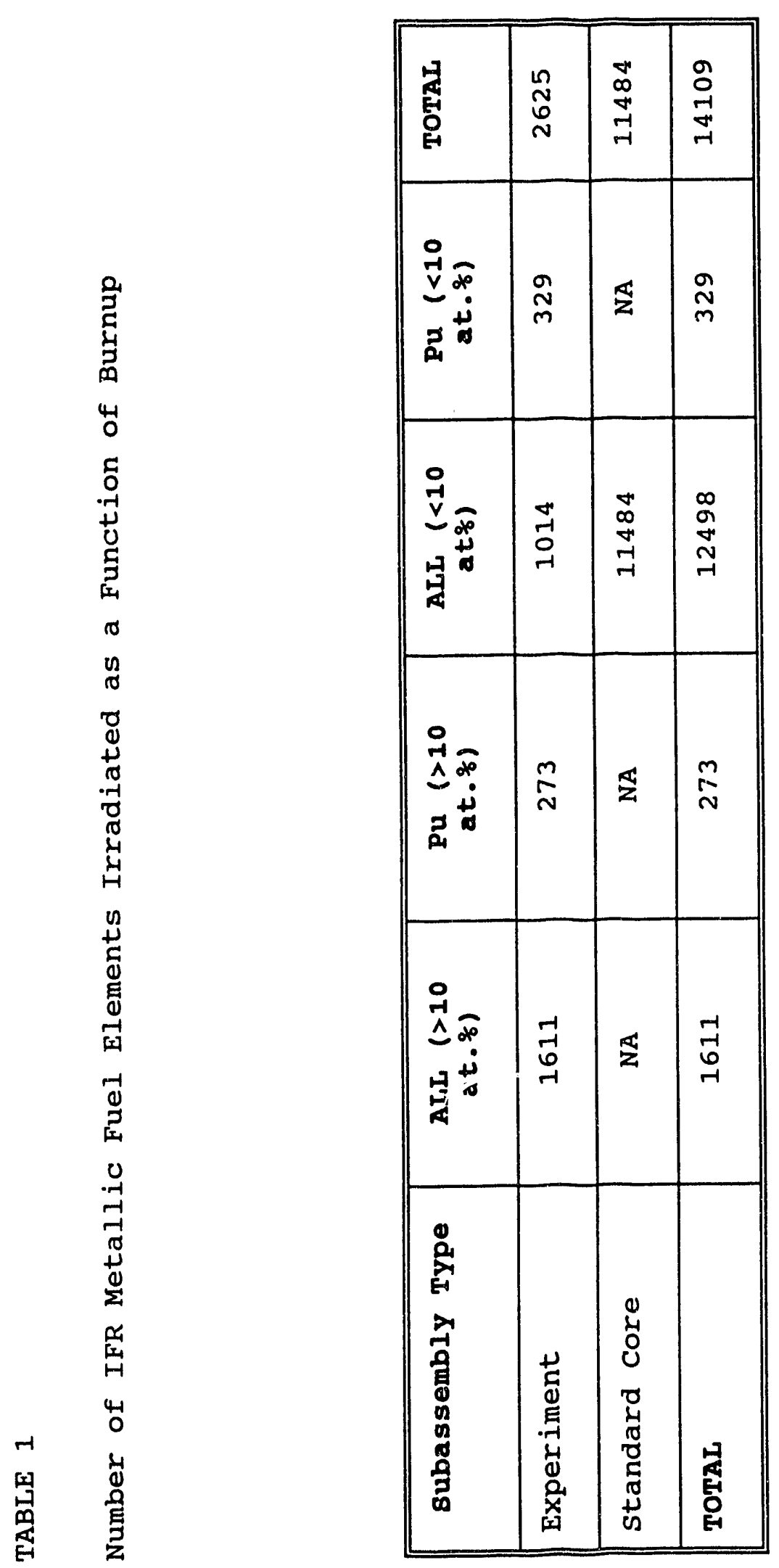




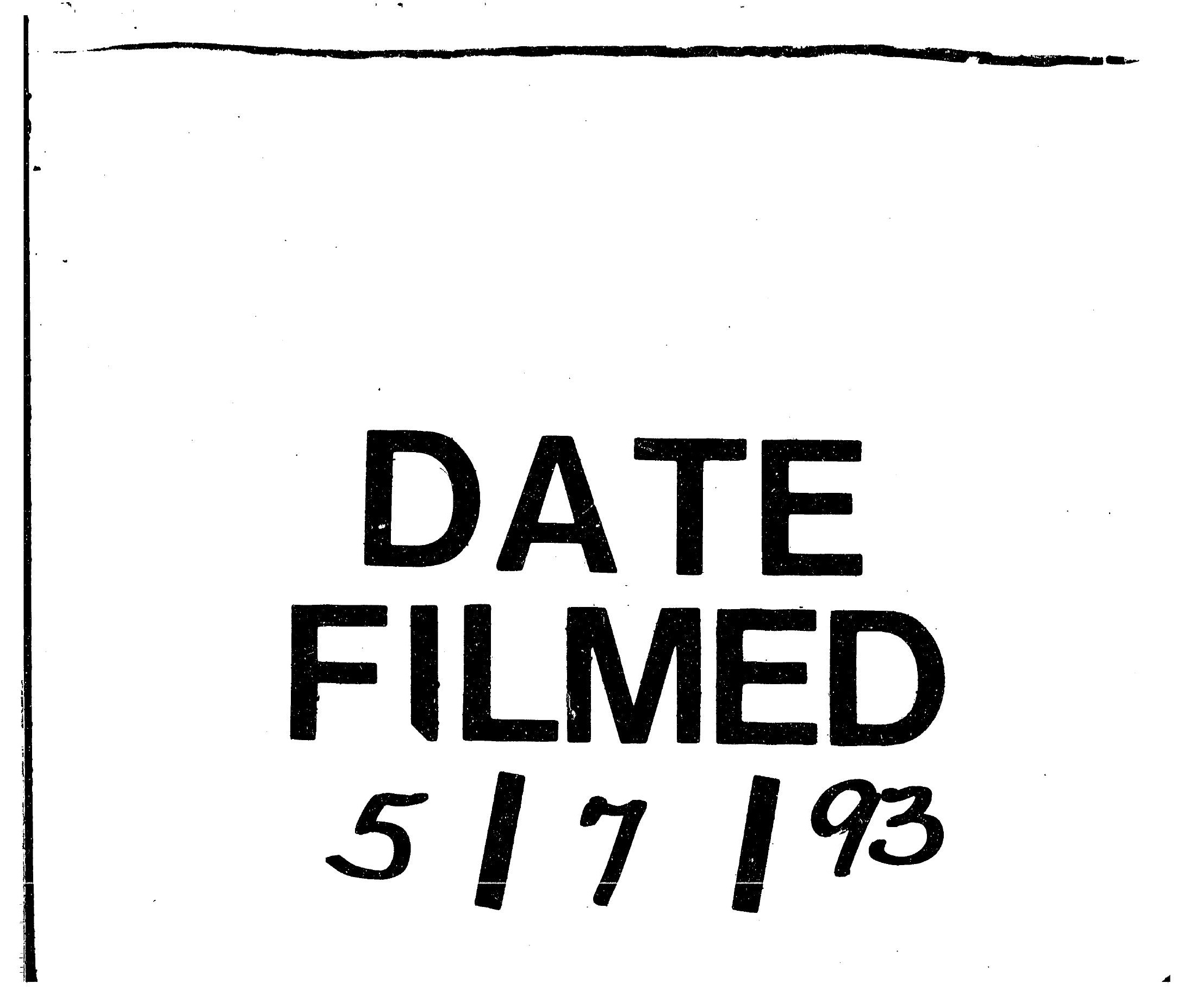


